\title{
4th International Consensus Conference on Advanced Breast Cancer (ABC4), Lisbon, November 4, 2017
}

\author{
ABC4 Consensus: Assessment by a Panel of German Experts*
}

\section{Internationale Konsensuskonferenz zum fortgeschrittenen Mammakarzinom (ABC4), Lissabon, 04.11.2017}

\author{
ABC4-Konsensus: Bewertung durch eine deutsche Expertengruppe
}

\section{(ㄷ) (i) ()ㅇㅇ $\Theta$}

\section{Authors}

Michael Untch ${ }^{1}$, Rachel Würstlein ${ }^{2}$, Norbert Marschner ${ }^{3}$, Diana Lüftner ${ }^{4}$, Doris Augustin ${ }^{5}$, Susanne Briest ${ }^{6}$, Johannes Ettl| ${ }^{7}$, Renate Haidinger ${ }^{8}$, Lothar Müller ${ }^{9}$, Volkmar Müller ${ }^{10}$, Eugen Ruckhäberle ${ }^{11}$, Nadia Harbeck ${ }^{12}$, Christoph Thomssen ${ }^{13}$

Affiliations

1 Klinik für Gynäkologie, HELIOS Klinikum Berlin-Buch, Berlin, Germany; Writing Committee

2 Brustzentrum und CCC München, Klinikum der Universität München, Klinik und Poliklinik für Frauenheilkunde und Geburtshilfe, München, Germany; Writing Committee

3 Gemeinschaftspraxis für interdisziplinäre Onkologie und Hämatologie, Freiburg, Germany; Writing Committee

4 Medizinische Klinik mit Schwerpunkt Hämatologie, Onkologie und Tumorimmunologie, Charité Berlin, Campus Benjamin Franklin, Berlin, Germany; Writing Committee

5 Mammazentrum Ostbayern, DONAUISAR Klinikum Deggendorf, Deggendorf, Germany

6 Universitätsfrauenklinik Leipzig, Leipzig, Germany

7 Frauenklinik und Poliklinik für Frauenheilkunde und Geburtshilfe, Klinikum rechts der Isar, München, Germany

8 Patientenvertreterin, Brustkrebs Deutschland e. V.; Patient Advocacy Committee ABC4, Faculty

9 Onkologische Schwerpunktpraxis Leer-Emden-Papenburg, Leer, Germany

10 Universitätsfrauenklinik Hamburg-Eppendorf, Hamburg, Germany

11 Frauenklinik, Universitätsklinikum Düsseldorf, Düsseldorf, Germany

12 Brustzentrum und CCC München, Klinikum der Universität München, Klinik und Poliklinik für Frauenheilkunde und Geburtshilfe, München, Germany; Writing Committee, ABC Panel Member, ABC Scientific Committee Member

13 Universitätsklinik und Poliklinik für Gynäkologie, MartinLuther-Universität, Halle an der Saale, Germany; Writing Committee, ABC Panel Member

Key words

$A B C 4$, local advanced and metastasized breast cancer ( $A B C)$, HR-positive and HER2-negative ABC, BRCA-mutated ABC, CNS metastasis, personalized medicine
Schlüsselwörter

$A B C 4$, lokal fortgeschrittenes und metastasiertes Mammakarzinom ( $A B C)$, HR-positiv und HER2-negatives $A B C$, BRCA-mutiertes ABC, ZNS-Metastasen, personalisierte Medizin

received 26.1.2018

revised 15.3.2018

accepted 18.3.2018

Bibliography

DOI https://doi.org/10.1055/a-0594-2243

Geburtsh Frauenheilk 2018; 78: 469-480 @ Georg Thieme Verlag KG Stuttgart · New York | ISSN 0016-5751

\section{Correspondence}

Prof. Dr. med. Michael Untch

Klinik für Gynäkologie, Interdisziplinäres Brustzentrum, HELIOS Klinikum Berlin-Buch Schwanebecker Chaussee 50, 13125 Berlin, Germany michael.untch@helios-gesundheit.de

$\Theta$ Deutsche Version unter: https://doi.org/10.1055/a-0594-2243 


\section{ABSTRACT}

The fourth international advanced breast cancer consensus conference $(A B C 4)$ on the diagnosis and treatment of advanced breast cancer $(A B C)$ headed by Professor Fatima Cardoso was once again held in Lisbon on November 2-4, 2017. To simplify matters, the abbreviation $A B C$ will be used hereinafter in the text. In clinical practice, the abbreviation corresponds to metastatic breast cancer or locally far-advanced disease. This year the focus was on new developments in the treatment of $A B C$. Topics discussed included the importance of CDK4/6 inhibition in hormone receptor (HR)-positive $A B C$, the use of dual antibody blockade to treat HER2-positive $A B C$, PARP inhibition in triple-negative $A B C$ and the potential therapeutic outcomes. Another major area discussed at the conference was BRCA-associated breast cancer, the treatment of cerebral metastasis, and individualized treatment decisions based on molecular testing (so-called precision medicine). As in previous years, close cooperation with representatives from patient organizations from around the world is an important aspect of the $A B C$ conference. This cooperation was reinforced and expanded at the ABC4 conference. A global alliance was founded at the conclusion of the consensus conference, which aims to promote and coordinate the measures considered necessary by patient advocates worldwide. Because the panel of experts was composed of specialists from all over the world, it was inevitable that the $A B C$ consensus also reflected country-specific features. As in previous years, a team of German breast cancer specialists who closely followed the consensus voting of the $A B C$ panelists in Lisbon and intensively discussed the votes has therefore commented on the consensus in the context of the current German guidelines on the diagnosis and treatment of breast cancer [1,2] used in clinical practice in Germany. The $A B C$ consensus is based on the votes of the $A B C$ panelists in Lisbon.

\section{ZUSAMMENFASSUNG}

Vom 2. bis 4. November 2017 fand in Lissabon erneut unter Leitung von Frau Professor Fatima Cardoso die 4. Internationale Konsensuskonferenz ABC4 (Advanced Breast Cancer Forth Consensus) zu Diagnostik und Behandlung des fortgeschrittenen Mammakarzinoms ( $A B C$ ) statt. Zur Vereinfachung wird im weiteren Text von $A B C$ gesprochen, was im klinischen Alltag der metastasierten Brustkrebserkrankung oder der lokal weit fortgeschrittenen Erkrankung entspricht. Der inhaltliche Schwerpunkt lag dieses Jahr auf neuen Entwicklungen in der Behandlung des ABC. Diskutiert wurden unter anderem der Stellenwert der CDK4/6-Inhibition beim hormonrezeptor-(HR-)positiven ABC, die duale Antikörperblockade beim HER2-positiven ABC, die PARP-Inhibition beim BRCAmutierten tripel-negativen und luminalen $A B C$ sowie potenzielle therapeutische Konsequenzen. Ein weiterer Fokus lag auf dem BRCA-assoziierten Mammakarzinom, der Behandlung von Hirnmetastasen sowie der individualisierten Therapieentscheidung auf der Grundlage einer molekularen Testung (sog. Präzisionsmedizin). Wie schon in den vergangenen Jahren ist die Zusammenarbeit mit den Vertretern von Patientenorganisationen aus aller Welt ein wichtiges Anliegen der ABC-Konferenz. Sie wurde auf der ABC4-Konferenz weiter intensiviert. Im Anschluss an die Konsensuskonferenz wurde die „Global Alliance“ gegründet mit dem Ziel, die erforderlichen Maßnahmen aus Sicht der Patientenvertreterinnen weltweit zu propagieren und zu koordinieren. In den ABC-Konsensus fließen aufgrund des international zusammengesetzten Expertenpanels zwangsläufig länderspezifische Besonderheiten ein. Wie schon in den vergangenen Jahren hat daher eine Arbeitsgruppe deutscher Brustkrebsexperten, welche die Konsensusabstimmung der ABC-Panelisten vor Ort mitverfolgt und intensiv diskutiert haben, diese unter Berücksichtigung der deutschen Leitlinien zu Diagnostik und Therapie des Mammakarzinoms [1,2] für den Therapiealltag in Deutschland kommentiert. Die Abstimmungsergebnisse der ABC-Panelisten in Lissabon sind die Grundlage des ABC-Konsensus.

\section{Introduction}

The international ABC (Advanced Breast Cancer) consensus conference focuses on the diagnosis and treatment of advanced breast cancer and has been held in Lisbon every two years since 2011. The aim of the $A B C$ consensus is to harmonize and standardize the care of patients with locally advanced and/or metastatic breast cancer $(A B C)$ all over the world. A group of international experts came together for the fourth time in Lisbon on November 2-4, 2017.
The interdisciplinary 2017 ABC panel consisted of 42 international breast cancer specialists and included five patient representatives and one specialist oncology nurse (see box). There were two breast cancer specialists from Germany on the ABC4 panel in the persons of Prof. Nadia Harbeck, Munich, and Prof. Christoph Thomssen, Halle/Saale. Prof. Harbeck was additionally a member of the 3-person strong scientific committee of the ABC4 conference. Renate Haidinger (Brustkrebs Deutschland e. V.), attending for the first time, was present as a member of the Patient Advocacy Committee of the ABC4 and the Faculty. 


\section{ABC4 PANELISTS}

1. Fatima Cardoso, PT (chair, coordination)

2. Eric P. Winer, US (chair)

3. Alberto Costa, $\mathrm{CH} / \mathrm{IT}$ (chair)

4. Larry Norton, US (chair)

5. Elzbieta Senkus-Konefka, PL (co-chair, ESMO)

6. Evi Papadopoulos, CY (co-chair, patients' representative)

7. Matti S. Aapro, CH (scientific committee)

8. Nadia Harbeck, DE (scientific committee)

9. Fabrice André, FR (scientific committee)

10. Musa Mayer, US (patients' representative)

11. Daniell Spence, AU (patients' representative)

12. Bertha Aguilar Lopez, MX (patients' representative)

13. Gertrude Nakigudde, UG (patients' representative)

14. Christine B. Boers-Doets, NL (specialist nurse)

15. Lesley Fallowfield, UK (psycho-oncologist)

16. Bella Kaufman, IL

17. Olivia Pagani, $\mathrm{CH}$

18. George W. Sledge, US

19. Carlos H. Barrios, BR

20. Laura Biganzoli, IT

21. Maria João Cardoso, PT

22. Lisa Carey, US

23. Javier Cortés, ES

24. Giuseppe Curigliano, IT

25. Véronique Dieras, FR

26. Nagi El Saghir, LB

27. Prudence A. Francis, AU

28. Karen Gelmon, CA

29. Smruti Koppikar, IN

30. Birgitte V. Offersen, DK

31. Shani Paluch-Shimon, IL

32. Frédérique Penault-Llorca, FR

33. Christoph Thomssen, DE

34. Daniel A. Vorobiof, ZA

35. Stephen RD Johnston, UK

36. Jonas Bergh, SE

37. Alex Eniu, RO

38. Aleix Prat, ES

39. Hope S. Rugo, US

40. Ian E. Krop, US

41. Shinji Ohno, JP

42. Binghe $\mathrm{Xu}, \mathrm{CN}$

The main focus of the latest $A B C 4$ consensus conference was on new developments in the treatment of advanced and metastatic breast cancer. Topics included new groups of substances such as inhibitors of cyclin-dependent kinases 4 and 6 (CDK4/6 inhibitors) and the impact of recent study data on treatment algorithms. The therapy of patients with BRCA-associated breast cancer and of patients with cerebral metastasis was discussed in detail. Another topic considered in more depth was precision medicine, which aims to individualize treatment decisions even more using molecular testing. Discussions with representatives from patient organizations from all over the world were also an important aspect of
- Table 1 Quality of evidence and grading system used by ABC4 panelists (modified from [29]).

\section{Quality of evidence}

\begin{tabular}{|l|l|}
\hline I & $\begin{array}{l}\text { Evidence from at least one large, randomized, controlled } \\
\text { study of good methodological quality (low potential for bias) } \\
\text { or from meta-analyses of well-conducted randomized trials } \\
\text { without heterogeneity }\end{array}$ \\
\hline II & $\begin{array}{l}\text { Small randomized studies or large randomized studies with } \\
\text { a suspicion of bias (lower methodological quality) or meta- } \\
\text { analyses of such trials or of trials with demonstrated hetero- } \\
\text { geneity }\end{array}$ \\
\hline III & Prospective cohort studies \\
\hline IV & Retrospective cohort studies or case-control studies \\
\hline V & \begin{tabular}{l} 
Studies without a control group, case reports, expert opinions \\
\hline Strength of recommendation
\end{tabular} \\
\hline A & $\begin{array}{l}\text { Strong evidence of efficacy with substantial clinical benefit, } \\
\text { strongly recommended }\end{array}$ \\
\hline B & $\begin{array}{l}\text { Strong or moderate evidence of efficacy but with limited } \\
\text { clinical benefit, generally recommended }\end{array}$ \\
\hline C & $\begin{array}{l}\text { Insufficient evidence of efficacy or benefit does not outweigh } \\
\text { the risks or disadvantages (adverse events, costs, ...), optional }\end{array}$ \\
\hline D & $\begin{array}{l}\text { Moderate evidence for lack of efficacy or adverse outcome, } \\
\text { not generally recommended }\end{array}$ \\
\hline E & $\begin{array}{l}\text { Strong evidence for lack of efficacy or adverse outcome, } \\
\text { should never be recommended }\end{array}$ \\
\hline $\begin{array}{l}\text { Adapted with permission from the Infectious Diseases Society } \\
\text { of America-United States Public Health Service Grading System } \\
\text { (modified from [29]) }\end{array}$ \\
\hline
\end{tabular}

the $A B C$ conference, and the cooperation with patient advocacy organizations was intensified.

The $A B C$ conference was organized by the European School of Oncology (ESO) in cooperation with the European Society of Clinical Oncology (ESMO). As in previous years, the recommendations of the 2017 ABC4 consensus conference are published in the peer-reviewed journal The Breast* [3-5]. Publication is done in consultation with various international professional associations and patient advocacy organizations.

The aim of the ABC conference was to develop a basis for individual, evidence-based treatment decisions. Statements presented for the panelists in Lisbon to vote on were discussed by the panelists, who then had the choice of voting "yes" (agreement), "no" (disagreement) or "abstain". This year, panelists were given a further alternative when evaluating certain questions: "insufficient data". This option could be chosen when a panel member was of the opinion that the data was insufficient to allow a clearcut vote of "yes" or "no". Another new feature was the introduction of a new evidence and grading system, based on the treatment guidelines of the ESMO [6] ( $\bullet$ Table 1 ).

To avoid redundancies, only recent issues were voted on at the $\mathrm{ABC} 4$ conference. Statements from the previous ABC1-2-3 conferences which were not voted on again continue to be valid. The $\mathrm{ABC} 4$ panelists were requested to base their votes on existing, evi- 
dence-based data from clinical studies. Whether the specific treatment option was available in every country or not was irrelevant. The aim must be to ensure that medically necessary treatment options become available in those countries where they are currently not available. Issues concerning healthcare policies were not and are not discussed during consensus discussions.

The rationale for this publication was to provide a comment on the $A B C 4$ voting results in the context of existing German guidelines and recommendations [1,2] and to make suggestions for standard clinical practice in Germany. This is useful as the voting results were based on the opinions of specialists working in different fields and included country-specific points of view. In this publication, the German experts have focused on the results of the votes in Lisbon. Subsequent proposals put forward by the ABC4 panel for inclusion in the planned publication of the consensus are not the subject of this article.

\section{Hormone Receptor-positive, HER2-negative (HR+/HER2-) ABC}

\section{Ovarian function suppression (OFS)}

Premenopausal patients with HR+/HER2- (negative human epidermal growth factor receptor 2) advanced breast cancer are often not randomized in endocrine treatment studies, which is why study data on the treatment of these women are limited. Given this situation, the overwhelming majority (94.5\%) of ABC4 panelists emphasized that premenopausal patients needed adequate suppression of ovarian function (OFS) and, after OFS, should then receive the same treatment like postmenopausal patients. The ABC4 panel recommended treatment with an endocrine substance with/without additional targeted therapy. If premenopausal patients refuse OFS, treatment with tamoxifen remains the only but less efficacious option (91.6\%). The panel (91.8\%) also emphasized the necessity of designing future studies on the use of new endocrine-based treatment strategies in such a manner that pre- and postmenopausal patients can be included in the studies (level of evidence [LoE]: expert opinion).

The German expert group agrees with all three statements and refers to the BCY3 Consensus (Breast Cancer Young Patients) [7] which also concurs with this recommendation.

\section{Use of everolimus}

Patients with endocrine-resistant HR+/HER2- metastatic breast cancer are likely to have a significantly longer median progression-free survival (PFS) compared to aromatase inhibitor monotherapy if they receive the mTOR (mammalian target of rapamycin) inhibitor everolimus in addition to an aromatase inhibitor (AI). Even though a median survival benefit has not been shown, the combination of $\mathrm{Al}+$ everolimus can be a valid treatment option for some patients, according to the majority vote (87.8\%; abstentions: 9.7\%). However, the ABC4 panelists pointed out that, because of the lack of a survival benefit, when taking the decision for or against this treatment, special attention must be paid to potential side effects (LoE: 1B). The majority of $A B C 4$ panelists (79.4\%; abstentions: 15.3\%) viewed tamoxifen (LoE: 2B) and ful- vestrant (LoE: expert opinion) as additional substances which could be combined with everolimus.

A combination with everolimus can also be an option for older patients. However the ABC4 panelists (97.4\%) recommended carrying out close monitoring with proactive management of side effects. They mentioned the increased toxicity, including toxic deaths in the everolimus arm of the BOLERO-2 trial $[8,9]$, which could be prevented by monitoring and proactive management. A combination of everolimus + Al was used in the BOLERO-2 trial.

The German specialists agree with all of these statements. However, the German specialists would like to add that the combinations fulvestrant + everolimus and tamoxifen + everolimus have not yet been approved for use in Germany. But the data [10], according to the German experts, support the vote of the ABC4 panel. In addition to the secondary prophylactic management of side effects, the German specialists recommend primary prophylactic measures (e.g. dexamethasone, mouthwashes) to prevent severe side effects. Meticulous oral hygiene is important, as the administration of the drug(s) must be discontinued if the patient develops an oral fungal infection.

\section{CDK4/6 inhibition plus aromatase inhibitors}

Based on a high level of evidence (LoE: $1 \mathrm{~A}$ ), a large majority of the ABC4 panelists recommended first-line treatment with a CDK4/6 inhibitor combined with an $\mathrm{Al}$ as the preferred treatment option (89.7\%, abstentions: $10.2 \%$ ). Only patients who experience disease progression within twelve months of adjuvant Al therapy were excluded from this recommendation. The ABC4 panelists justified their vote based on the significant median PFS benefit of around ten months following the addition of a CDK4/6 inhibitor, while the side-effects profile remained within acceptable limits [11 - 13]. In their quality of life analyses, patients reported a quality of life which was, at the very least, comparable to that experienced with endocrine therapy alone. Mature survival data from phase III studies are not yet available. During the discussion in Lisbon, the $A B C 4$ panelists pointed out that it was important that CDK4/6 inhibitors were available in all countries.

The German specialists agree with all of the above statements.

\section{CDK4/6 inhibition plus fulvestrant}

The combination of a CDK4/6 inhibitor with fulvestrant is the preferred option for patients with HR+/HER2- metastatic breast cancer who previously received endocrine-based treatment but did not previously receive a CDK4/6 inhibitor as first-line treatment (LoE: 1A). This applies irrespective of the patient's menopausal status. Premenopausal/perimenopausal patients additionally need OFS. The ABC4 panelists again assigned a high level of evidence to this statement (LoE: 1A) and justified their majority vote ( $90 \%$ in favor; abstentions: $10 \%$ ) by referring to the significant median PFS benefit of 6-7 months compared to endocrine therapy alone (fulvestrant) [14]. The ABC4 panelists pointed out that no mature survival data are available yet for this combination either.

The German experts agree that a CDK4/6 inhibitor should be added, at the latest when starting second-line endocrine therapy. In the opinion of the German specialists, median PFS is an important patient-focused study endpoint. An analysis of patients' qual- 
ity of life also showed benefits for a combination with fulvestrant compared to endocrine therapy alone [15].

\section{Therapy sequence after endocrine-based therapy}

It is currently not clear what the optimal therapy sequence for HR +/HER2- metastatic breast cancer is after endocrine-based firstline therapy. According to the majority vote $(94.7 \%$ in favor; abstentions: $5.2 \%$ ), pre-treatment in a (neo)adjuvant setting or firstline therapy for locally advanced stage cancer, the extent of disease, and the patient's own preference play an important role, along with the cost of treatment and its availability. It is important to refer to the fundamental statement by the $A B C 4$ panelists whereby the availability of treatment should play no role for consensus recommendations.

According to the majority vote $(73.6 \%$ in favor; abstentions: $21.0 \%$ ), the following therapies are potential options to treat patients with metastatic disease after they have received endocrinebased first-line therapy: tamoxifen, fulvestrant \pm CDK4/6 inhibitor or everolimus combined with an Al, tamoxifen or fulvestrant. The $A B C 4$ panelists recommend megestrol acetate and estradiol in later lines of therapy. They emphasize that there are no data from head-to-head studies comparing the different endocrine-based therapy options or with mono-chemotherapy ( \pm bevacizumab). We will have to wait for the results of current ongoing studies (LoE: 1A).

The German experts agree with the various statements but point out that there are currently no TBP (treatment beyond progression) data for targeted substances (CDK4/6 or mTOR inhibition). Moreover, based on the therapy recommendations of the German guideline commission (AGO Mamma) [1], the German specialists do not consider high-dose progestogens (megestrol acetate) and estradiol to be indicated - not even during later lines of therapy ( $\bullet$ Table 2 ).

\section{Selection criteria for endocrine-based therapy urgently needed}

With the exception of HR status, at present there are no validated predictive markers to identify those women who could benefit from endocrine-based therapy with a CDK4/6 or mTOR inhibitor. Research on this is needed, according to the majority vote $(95.0 \%$ in favor; abstentions: $5.0 \%$ ) of the ABC4 panelists (LoE: 1D).

The German experts also emphasize the need for more selection criteria (e.g., biomarkers, molecular factors, including molecular imaging, or the dynamics of the disease). In the opinion of the German experts, the issue is also about identifying those patients for whom initial treatment with endocrine monotherapy is sufficient and who do not require a first-line endocrine-based combination therapy.

\section{Fulvestrant as a first-line option?}

The question whether fulvestrant is an adequate first-line option for postmenopausal patients with HR+/HER2- metastatic breast disease who have not had prior endocrine therapy and who were unable to receive a CDK4/6 inhibitor during first-line therapy (LoE: $1 \mathrm{~B})$ was put to the panelists but then retracted during the discussions in Lisbon. The question was based on data from the FALCON trial [16]. In the trial, fulvestrant (500 mg) achieved a longer me-
- Table 2 Endocrine-based treatment options for postmenopausal patients with $\mathrm{HR}+/ \mathrm{HER} 2-$ metastatic breast cancer according to AGO Breast 2018 (modified from [1]).

\begin{tabular}{|c|c|c|c|}
\hline & \multicolumn{2}{|c|}{ Oxford } & \multirow[b]{2}{*}{ AGO } \\
\hline & LoE & GR & \\
\hline Letrozole* + palbociclib & $1 b$ & B & ++ \\
\hline Fulvestrant + palbociclib & $1 b$ & B & ++ \\
\hline Letrozole* + ribociclib & $1 b$ & B & ++ \\
\hline Letrozole/anastrozole + abemaciclib & $1 \mathrm{~b}$ & B & + \\
\hline Fulvestrant + abemaciclib & $1 b$ & B & + \\
\hline Abemaciclib monotherapy & 3 & C & $+1-$ \\
\hline Exemestane + everolimus & $1 b$ & A & + \\
\hline Tamoxifen + everolimus & $2 b$ & B & + \\
\hline Letrozole + everolimus & $2 b$ & B & $+1-$ \\
\hline Fulvestrant + everolimus & $2 b$ & B & + \\
\hline CDK4/6i beyond progression & 5 & D & - \\
\hline
\end{tabular}

dian PFS in these patients compared to first-line therapy with anastrozole, particularly in patients with no visceral metastasis (LoE: 1B). Although at present there are still no mature data on survival, it is expected that there will be some data in the near future. It would be best to wait for these results and include them in the consensus manuscript. It was also pointed out that the optimal therapy sequence is still unknown.

The German experts consider fulvestrant monotherapy as an alternative in the first-line setting of HR+/HER2- metastatic disease and recommend this treatment for individual patients, particularly patients without visceral metastasis. Patients need to be informed about the fact that there are currently no firm selection criteria which specific patients would benefit. Patients must also be informed about available therapy options in the first-line setting - including the use of endocrine-based targeted therapy and, after receiving adequate information, agree to monotherapy with fulvestrant.

\section{Hormone Receptor-positive and HER2-positive $(\mathrm{HR}+/ \mathrm{HER} 2+) \mathrm{ABC}$}

\section{Endocrine therapy plus HER2 blockade}

The following opening statement was the basis for the $A B C 4$ votes on $\mathrm{HR}+/ \mathrm{HER} 2+$ metastatic breast cancer: women with $\mathrm{HR}+/ \mathrm{HER} 2+$ metastatic breast cancer who receive endocrine therapy instead of chemotherapy are a highly selected group of patients. Endocrine therapy should be combined with an anti-HER2 substance (trastuzumab or lapatinib) as this combination offers a PFS benefit compared to endocrine therapy alone and also results in a longer 
period of time without chemotherapy (LoE: 1A). Additional antiHER2 therapy has not been shown to offer a benefit in terms of overall survival. However, the available studies do not include long-term follow-up. The strategy of combined endocrine/antiHER2 therapy is currently being compared to a combination treatment consisting of chemotherapy plus anti-HER2 substances in large controlled studies.

Given this context, a large majority of ABC4 panelists (80.4\%) voted to combine endocrine therapy with a dual HER2 blockade (trastuzumab/pertuzumab or trastuzumab/lapatinib) as this treatment offers patients the possibility of a longer PFS. The decision in favor of dual anti-HER2 therapy must be made considering that the range of side effects may potentially be higher, treatment is more expensive, and an additional survival benefit has not been proven to date.

The German experts wish to add that dual anti-HER2 therapy combined with taxane-based chemotherapy is currently the standard approach for patients with $\mathrm{HR}+/ \mathrm{HER} 2+$ metastatic breast cancer as this treatment offers a significant survival benefit [1]. Contraindications against taxane chemotherapies such as weekly paclitaxel as favored in Germany are very rare. If the patient rejects chemotherapy, she must be informed that no survival benefit has been shown for endocrine therapy combined with HER2targeted substance. The German specialists recommend including patients with $\mathrm{HR}+/ \mathrm{HER} 2+$ metastatic breast cancer in the randomized DETECT V/CHEVENDO trial, in which women receive dual HER2 blockade (trastuzumab/pertuzumab) combined with endocrine therapy or chemotherapy. The focus of DETECT $V$ is on the quality of life of patients in both study arms.

\section{Anti-HER2 maintenance therapy}

According to the majority vote of the ABC4 panelists (in favor: $80.4 \%$; abstentions: $17.0 \%$ ), after completing chemotherapy, endocrine maintenance therapy plus continued HER2 blockade is the best strategy for patients with $\mathrm{HR}+/ \mathrm{HER} 2+$ metastatic breast cancer who were successfully treated with chemotherapy plus anti-HER2 therapy, even if there are no randomized study data available yet. The optimal duration of maintenance therapy needs to be validated in clinical studies. The current approach is that maintenance therapy should only be discontinued following progression if the side effects are inacceptable or at the request of the patient.

The German specialists agree with this statement.

\section{Advanced or Metastatic Triple-negative Breast Cancer (TNBC)}

\section{Relevance of androgen receptors (AR)}

Patients with advanced or metastatic TNBC and androgen receptor positive $(A R+)$ tumors who no longer respond to standard therapies have a particularly poor prognosis. In this context the ABC4 panelists discussed whether, for these patients, treatment with the AR inhibitor bicalutamide ( $150 \mathrm{mg}$ per day) is indicated in individual cases. The importance of AR inhibition has not yet been validated in randomized phase III studies for AR+ metastatic TNBC (mTNBC).

In a statement amended during the conference in Lisbon, the majority of $A B C 4$ panelists (in favor: $85.3 \%$; abstentions: $14.6 \%$ ) assessed $A R$ as a potential target in AR+ TNBC but emphasized that there is no standard method to measure AR expression. Limited data show some efficacy for the (2nd generation) AR inhibitors bicalutamide und enzalutamide. However, data from more studies is required, which is why AR inhibitors should not be routinely used in clinical practice. The ABC4 panelists call for more research and clinical studies.

The German experts recommend in individual cases bicalutamide as a treatment option after standard therapies have been exhausted for patients with AR+ mTNBC who have been appropriately informed. The German specialists wish to add that at present there is no predictive AR test. They confirm that immunohistochemical testing of AR positivity has not been validated. The development of enzalutamide for breast cancer has been discontinued, no further study data on AR inhibition are expected in the near term.

\section{BRCA-associated ABC}

\section{Early genetic testing}

For patients with $A B C$ and a positive familial history, all $A B C 4$ panelists (100\%!) recommend early genetic testing, as the results of the test can affect the decision for treatment. The ABC4 panelists called for the recommendation that these women have genetic testing to be included in international and national guidelines (LoE: expert opinion).

The German experts agree with both statements and mention the German guidelines [1,2]. It is currently recommended in Germany that patients with a family risk, patients with TNBC (without age limits and irrespective of family history) and very young patients (aged $<35$ years, also without a positive family history) have genetic testing. Patients should be referred for testing to specialized breast centers or to a geneticist. The treatment options proposed by the AGO are listed in > Table 3 [1].

\section{Only BRCA1/2 germline testing validated to date}

The ABC4 panelists unanimously (100\%!) agreed that genetic testing should be done based on positive (family) history. They also pointed out that currently only BRCA $1 / 2$ germline mutations have a therapeutic impact and that testing for these mutations offers a clinical benefit. Testing for other moderate-to-high risk genes can be considered after consultation with a geneticist. In these cases, patients must be informed about the fact that, at present, the test results have no direct effect on treatment but could benefit family members (LoE: expert opinion).

In a further statement the majority of $A B C 4$ panelists $(82.5 \%$ in favor; abstentions: $15.0 \%$ ) agreed that somatic BRCA1/2 mutation testing should not be used in routine clinical practice. Any potential therapeutic consequences of such testing must be investigated further under research conditions (LoE: expert opinion).

The German experts again agree with the majority vote of the $\mathrm{ABC} 4$ panelists. They confirm that BRCA testing in tumor tissue 
does not currently have any therapeutic consequences for breast cancer patients. They do, however, wish to point out that not all tumor mutations are detectable by germline testing [17]. The clinical relevance of testing tumor tissue should therefore be investigated further in controlled clinical studies.

\section{Impact of PARP inhibition}

The poly (ADP-ribose) polymerase (PARP) inhibitor olaparib has been recently approved by FDA to treat $A B C$. However, the majority of $A B C 4$ panelists (in favor: $80.0 \%$; abstentions: $17.5 \%$ ) consider olaparib to be a useful treatment option for patients with advanced or metastatic BRCA mutated TNBC or luminal-like breast cancer. Patients should receive pretreatment in the form of (neo)adjuvant therapy or as a first-line therapy with anthracyclines plus/minus taxanes for metastatic disease and must not have platinum-resistant disease.

The ABC4 panelists referred to the phase III OlympiAD trial and justified their vote by noting that olaparib has a good side-effects profile and offers patients the chance of a longer PFS and an improved quality of life compared to chemotherapy. Data on patients' overall survival rates are not yet available. Post hoc meeting: results are now available and show favourable outcome. It is also not yet clear how well PARP inhibitors perform compared to platinum (LoE: 1A). According to the ABC4 panelists' discussion in Lisbon, those patients for whom olaparib might be a treatment option need to be defined (more) precisely.

In principle, the German experts agree with the above statements. They emphasize that olaparib has not yet been approved to treat $A B C$ and is therefore currently only an option in clinical practice in individual cases (an application for off-label use is required). The European approval is expected for end of 2018. Talazoparib is also currently not approved. Very good data from the EMBRACA trial [18] on the PARP inhibitor talazoparib were presented at 2017 San Antonio Breast Cancer Meeting.

\section{Biosimilars}

With a clear majority (in favor: $90.2 \%$; abstentions: $7.3 \%$ ) the ABC4 panelists strongly recommended the use of biosimilars, both for the treatment of breast cancer (e.g. trastuzumab) and for use in supportive therapies (e.g. growth factors). The precondition for biosimiliar use is that the substance has been approved and has successfully passed through the mandated stringent development and validation process of the EMA (European Medicines Agency), the FDA (Food and Drug Administration) or a comparable institution (LoE: 1A).

The German experts agree. They point out that the first biosimilars were approved to treat breast cancer in November 2017.

\section{Precision Medicine}

\section{Multigene panel testing}

The importance of multigene test procedures (for example NGS [next generation sequencing] or other technologies at the tumor DNA level) has been discussed in clinical practice since several years. The rationale behind this is that the procedures could be
- Table 3 Treatment options for BRCA1/2-associated breast cancer according to AGO Mamma 2018 (modified from: [1]).

\begin{tabular}{|c|c|c|c|}
\hline \multicolumn{4}{|c|}{ Treatment of BRCA1/2-associated breast cancer } \\
\hline & \multicolumn{2}{|c|}{ Oxford } & \multirow[b]{2}{*}{ AGO } \\
\hline & LoE & GR & \\
\hline \multicolumn{4}{|l|}{$\begin{array}{l}\text { Prospective cohort studies with a } \\
\text { limited follow-up period are available }\end{array}$} \\
\hline $\begin{array}{l}\text { - breast-conserving surgery: } \\
\text { adequate local tumor control } \\
\text { ( 10 years' follow-up) }\end{array}$ & $2 a$ & B & + \\
\hline $\begin{array}{l}\text { - systemic therapy in accordance } \\
\text { with general standards }\end{array}$ & $3 a$ & B & + \\
\hline $\begin{array}{l}\text { gBRCA1 mutation status is a } \\
\text { predictive factor for the response } \\
\text { to chemotherapy of patients with } \\
\text { TNBC }\end{array}$ & $2 b$ & B & + \\
\hline $\begin{array}{l}\text { - carboplatin (vs. docetaxel) } \\
\text { for metastatic breast cancer }\end{array}$ & $2 b$ & B & + \\
\hline $\begin{array}{l}\text { PARP inhibitor for metastatic } \\
\text { breast cancer } \\
\text { + overall prognosis must be taken } \\
\text { into account }\end{array}$ & $1 b$ & A & + \\
\hline
\end{tabular}

the basis for the selection of patients and for personalized treatment decisions. A significant majority (82.9\%) of the ABC4 panelists think that multigene testing is currently not an option in routine clinical practice. The panelists point out that controlled clinical studies have not yet been able to show that such testing offers any benefit to patients, and it is not clear whether such testing has a beneficial impact on prognosis.

Notwithstanding the above caveat, the ABC4 panelists approved the use of NGS in the context of prospective molecular studies to select patients for therapeutic trials. This assumes that the patient will be prepared to take part in clinical trials investigating new treatment options and is willing to be treated at a center which participates in the corresponding clinical trials and registers and is experienced in submitting requests and using an off-label drug. According to the majority vote of the $A B C 4$ panelists, test procedures which were specially developed and validated for the use of particular medicines will play a role in clinical practice as soon as such a drug has been officially approved for use (LoE: 1D).

The German experts agree with the above statements but wish to point out that there is currently no registry with the relevant patient data in Germany. Multigene testing in Germany should preferably be carried out in comprehensive cancer centers (CCCs) with molecular tumor boards which include a gynecologic oncologist. This would make it easier to set up the necessary databases and biobanks. The benefits of clinical and translational registers is already emerging in the ongoing PRAEGNANT trial.

\section{Should circulating tumor DNA be evaluated?}

The evaluation of circulating tumor DNA (ctDNA) is not an option in clinical practice, and it was not recommended by the ABC4 panelists, neither to detect disease progression nor to help select targeted therapy (agreement: $74.3 \%$; abstentions: 10.2\%; insuffi- 
cient data: $15.3 \%$ ) (LoE: 1D). The German experts agree with this statement and point out that the clinical role of ctDNA and of CTC analysis (CTC: circulating tumour cells) is currently being investigated in German study centers in the context of translational research projects in large clinical studies (cf. DETECT, PRAEGNANT).

\section{Microsatellite instability in breast cancer}

The importance and consequence of high-frequency microsatellite instability (MSI-H/MMRD) are still controversially discussed, and the $A B C 4$ panelists did not reach a majority decision; for more than $40 \%$ of the ABC4 panelists (41.4\%), PD-1 (programmed cell death-1) targeted drugs (so-called PD-1 inhibitors) are a possible option for these patients (LoE: expert opinion). Just under half of the ABC4 panelists (48.7\%) did not agree because they considered that the data is still insufficient. Almost $10 \%$ (9.7\%) abstained.

The German experts mentioned the Amsterdam II criteria which cited clinical criteria from the patient's own or her family's medical history which could indicate MSI positivity [19]. These criteria must be systematically included in the investigation of the medical history of every patient. The Amsterdam criteria are considered to set the standard for MSI testing. If test results are positive, the German specialists recommend, given the limited treatment options for these patients, PD- 1 targeted therapy with a PD-1 antibody such as pembrolizumab (cf. the current FDA approval) [20].

\section{NTRK fusion in breast cancer}

For patients with $A B C$ and NTRK gene fusion (NTRK = neurotrophic tyrosine receptor kinase) a simple majority of the $A B C 4$ panelists (47.3\%; abstentions: $23.6 \%$ ) think that the data are not sufficient to recommend the use of a selective TRK (tyrosine receptor kinase) inhibitor (entrectinib). Less than one third of the ABC4 panelists $(28.9 \%)$ were prepared to potentially consider the administration of a TRK inhibitor for these patients.

For the German specialists, NTRK fusion does not currently play any role in clinical practice. Moreover, the incidence of NTRK fusion is low. The question reflected potential future developments where molecular tumor boards are expected to play a greater role. It also underlined the importance of setting up German tumor registers for the relevant tumor data, as such registers could encourage the use of precision medicine for individualized treatment decisions in Germany.

\section{Immunotherapy for breast cancer}

Immunotherapy is already an important new therapeutic mainstay to treat various tumor entities. But as yet, there are still no adequately validated data on the use of immunotherapy to treat breast cancer. More than $80 \%$ of the ABC4 panelists (84.6\%) recommend that, with the exception of clinical trials, the use of immunotherapy is not indicated to treat advanced or metastatic breast cancer. Irrespective of the biological subtype, immunotherapy should not be used in routine clinical practice and should not be recommended. The $A B C 4$ panelists mentioned ongoing clinical studies which are evaluating the importance of immunotherapy for different subtypes of breast cancer (LoE: expert opinion).

The German experts agree with the majority vote of the ABC4 panelists. However, the German experts do not rule out the possibility that, after prior testing and receiving the patient's informed consent, immunotherapy could be an option in individual cases when standard therapies available have been exhausted and the individual patient's general condition and life expectancy support the use of immunotherapy. In such cases, it should be noted that, although serious new toxicities are rare, they are nevertheless possible, which is why this treatment approach requires a high level of oncologic expertise. The German experts add that at present no predictive biomarker has been validated for the use of immunotherapy in breast cancer treatment. The German experts emphasize that there are currently no validated data for breast cancer. The first results from phase III trials are expected in 2018.

\section{Treatment of Brain Metastases}

Radionecrosis following stereotactic radiation of brain metastases is a rare complication which can occur even many years after the administration of radiotherapy. As the survival times of patients with metastatic breast cancer have become longer, the risk has also increased, particularly for patients who had repeated radiotherapy of the brain. Making an accurate differential diagnosis (i.e., distinguishing radionecrosis from tumor progression) can be difficult. According to the majority vote of the ABC4 panelists $(60.5 \%$ in favor; abstentions: $31.5 \%$ ), high-dose steroids are the treatment of choice for symptomatic patients with radionecrosis. If the patients do not respond adequately to steroid treatment, the ABC4 panelists considered treatment with bevacizumab $(7.5 \mathrm{mg} / \mathrm{kg}$, every two weeks) to be an option, as this can reduce the increased cranial pressure in surrounding tissue. Patients should receive a median of 4 cycles of bevacizumab. Prospective randomized studies are necessary to validate further therapeutic options for this group of patients (LoE: IIIB).

The German experts add that radionecrosis is rare and the treatment must be discussed by an interdisciplinary tumor board.

\section{Brain metastases in HER2+ metastatic breast cancer}

If local measures to treat patients with advanced HER2+ breast cancer and progressive brain metastasis are no longer possible help and if the brain is the main area of metastasis, the overwhelming majority of the $A B C 4$ panelists $(85.0 \%)$ recommend to switch to systemic treatment (LoE: IIIA).

The ABC4 panelists additionally refer to earlier statements which continue to be valid:

1. Patients who have stable extracranial disease but develop brain metastasis should not change their systemic therapy if local therapeutic measures can be administered (LoE: 1C).

2. If the brain is the only site of metastasis for patients with HER2 + breast cancer, there are no indications that chemotherapy administered in addition to local treatment would change the course of disease. However, the recommendation is to restart anti-HER2-targeted therapy (trastuzumab) if they had previously interrupted anti-HER2-targeted therapy (LoE: 1C).

The German experts agree with the new statement and mention the effect of T-DM1 and lapatinib on progressive brain metastasis [21-24]. The treatment of brain metastasis must be discussed by an interdisciplinary group. Important data on the treatment of brain metastasis in women with breast cancer are expected from 
the Register of the German Breast Group (GBG) which was initiated and is maintained by the Department of Gynecology of the University Medical Center Hamburg-Eppendorf (Prof. Volkmar Müller, PD Dr. med. Isabell Witzel, University Medical Center Hamburg-Eppendorf).

\section{Important Definitions}

\section{Adequate suppression of ovarian function (OFS)}

What constitutes adequate OFS in premenopausal patients with advanced breast cancer was the subject of controversial discussions during the $A B C 4$ consensus vote. The following statement will be discussed again and may even be revised prior to publishing the consensus of the ABC4 panel.

Nevertheless, a majority of ABC4 panelists (in favor: $84.2 \%$; abstentions: $10.5 \%$ ) agreed with the statement proposed in Lisbon: adequate OFS can be achieved in premenopausal patients by bilateral ovariectomy, by continuous administration of a luteinizing hormone-releasing hormone (LHRH) agonist or by pelvic radiation of the ovaries (ovarian ablation). The ABC4 panelists mentioned that pelvic radiation was the least preferred option. For optimal results, systemic OFS using a gonadotropin-releasing hormone $(\mathrm{GnRH})$ agonist should be administered every 28 days in premenopausal women. Regular monitoring of follicle-stimulating hormone (FSH) and estradiol levels are recommended. This also applies to patients with therapy-induced amenorrhea.

The ABC4 panelists recommend in young women with endocrine-sensitive $A B C$ long-term OFS. When making a decision about the preferred method of OFS, the patient's wishes with regard to fertility preservation, patient compliance with monthly injections over a long period of time, the cost of treatment and possible surgical alternatives need to be weighed up.

The German experts emphasize that patients need to be monitored regularly and closely, especially at the beginning of $\mathrm{GnRH}$ agonist therapy (every 28 days). This particularly applies when the $\mathrm{GnRH}$ agonist is administered in combination with an Al. In such cases the German experts recommend closely monitoring patients' hormone status, including FSH and estradiol levels, for the first 3-6 months. According to the guidelines [1], long-term suppression of ovarian function is necessary in premenopausal patients receiving endocrine-based therapy. Bilateral salpingo-oophorectomy (BSO) should be discussed with these patients, as ovarian function suppression will need to be almost permanent. The German specialists mention patients with systemic OFS need to be informed about the need for reliable contraception (reference to statement on preserving fertility).

\section{Update on Locally Advanced Breast Cancer $(\mathrm{LABC})$}

\section{Duration of adjuvant HER2 blockade}

The ABC4 panelists defined $L A B C$ as inoperable, locally advanced breast cancer without distant metastasis. The overwhelming majority of ABC4 panelists (in favor: $84.6 \%$; abstentions: $15.3 \%$ ) agreed with the following statement about the duration of adjuvant HER2-targeted therapy for patients with inflammatory or non-inflammatory HER2+ LABC: if these patients are in complete remission after adequate neoadjuvant systemic therapy and subsequent loco-regional treatment, the optimal duration of adjuvant anti-HER2-targeted therapy is not clear. The ABC4 panelists therefore recommended defining the duration of adjuvant therapy according to the tolerability of treatment, the time and effort required, and the costs. Patients treated with curative intent should receive adjuvant anti-HER2 therapy for a total of one year (LoE: expert opinion).

The German experts wish to emphasize with reference to the current AGO recommendation [1] that adjuvant anti-HER2 therapy is limited to one year for patients treated with curative intent. Based on results from the APHINITY trial [25], adjuvant dual HER2 blockade in also an option for patients with $L A B C$ and a high risk of recurrence (lymph node involvement [N+], HR-). After one year of treatment with trastuzumab, subsequent therapy with neratinib could be considered for patients with HR+ HER2+ breast cancer [26].

\section{Inflammatory LABC}

There were no votes on the following two statements on inflammatory $\mathrm{LABC}$ at the $\mathrm{ABC} 4$ meeting in Lisbon because they were still the subject of controversial debate:

- There was a controversial discussion on whether breast-conserving surgery could be considered in individual cases with inflammatory $L A B C$ if the extent of the primary tumor was limited and complete regression of skin areas were achieved after systemic therapy, based on clinical examination and imaging (LoE: IIIB).

- The statement that sentinel lymph node biopsy (SLNB) is not an option for inflammatory $L A B C$ because of the high rate of false-negative findings was also controversially discussed. The high false-negative rate is due to lymphovascular tumor-related emboli in the parenchyma of the breast and skin which probably prevent normal lymphatic drainage into the axilla, making evaluation of the lymph nodes through imaging more difficult (LoE: IIID).

The German experts recommend neoadjuvant therapy followed by modified radical mastectomy (i.e. including axillary dissection) plus radiotherapy (chest wall and loco-regional lymph nodes) as standard therapy for inflammatory LABC [1].

\section{Sentinel lymph node biopsy in inoperable LABC}

A still valid $A B C$ consensus from previous years states that after effective neoadjuvant systemic treatment with/without radiotherapy, most patients with $L A B C$ with primarily inoperable disease will be able to undergo secondary surgery. As a rule these patients have a modified radical mastectomy. Breast-conserving surgery plus axillary dissection can be considered in individual cases (if the patient responds well to preoperative treatment) (LoE: 2B).

In this context the $\mathrm{ABC} 4$ panelists agreed on the following new statement: if patients with a low axillary tumor load or clinically unsuspicious axilla ( $\mathrm{cN} 0-\mathrm{cN} 1)$ at primary diagnosis achieve complete remission (ycN0) following neoadjuvant systemic therapy, 
sentinel lymph node biopsy (SLNB) may be an option. However, this requires SLNB to be carried out in accordance with the guidelines and recommendations for SLNB after primary systemic therapy. This includes marking with blue dye and technetium, clipping or marking of suspicious lymph nodes, and the resection of at least 3 sentinel lymph nodes during surgery after neoadjuvant therapy (LoE: IIIA). Two thirds of the ABC4 panelists $(62.1 \%$ in favor; abstentions: $21.6 \%$ ) agreed with this statement.

The German experts mention the German AGO recommendations, according to which axillary dissection is the standard procedure for primary inoperable and secondarily operable LABC. Alternatively, when lymph nodes are clinically and sonographically normal, sentinel surgery may be carried out in individual cases. However, the previously suspicious and affected lymph nodes would have to be marked and removed $[1,2]$.

\section{General Statements}

\section{Almost no changes in chemotherapy treatment}

Chemotherapy is a central pillar for the treatment of LABC and metastatic breast cancer. The ABC4 consensus only issued a modified statement on metronomic chemotherapy. The statements of previous $A B C$ consensus conferences are still valid.

The German experts additionally refer to the current German recommendations by AGO [1] and the S3 guideline on the treatment of patients with breast cancer [2].

In the opinion of the German specialists, metronomic chemotherapy is a useful approach for patients with metastatic breast cancer [1]. The prepared statement was not voted on at the ABC4 meeting as a data update is expected soon.

\section{Fertility preservation in women with advanced breast cancer}

The German experts agree with the ABC4 statement that the question of fertility preservation must be addressed with patients of child-bearing age (and their partners) before the start of therapy and discussed in the context of metastatic and advanced disease. All of the ABC4 panelists (100\%!) agreed and additionally suggested that discussions with these patients should also include information about the further prognosis and potential consequences of a pregnancy, for example, the potential interruption of ongoing therapy due to pregnancy (LoE: expert opinion). The German specialists add that the reduced life expectancy of women and the adverse effect on prognosis of potentially interrupting therapy and on the reduced life expectancy of the patients need to be addressed.

\section{Importance of Integrative Medicine}

According to the current general statement of the ABC4 consensus, complementary and integrative medicine (CIM) means the use of complementary therapies together with conventional therapies (LoE: expert opinion). The published consensus manuscript will contain further statements on integrative medicine. There was no time to vote on integrative medicine at the conference in Lisbon. For the German specialists, the term "integrative medicine" describes the use of complementary methods in addition to standard therapies. For further information, the German experts refer, in addition to the AGO recommendation [1], to the “Onkopedia Leitlinie Komplementärmedizin" [27] and to "Colloquium Senologie 2017/2018” [28].

\section{Supportive und Palliative Treatment}

Because of time constraints, the ABC4 conference did not vote on supportive therapy and palliative treatment for $A B C$ patients. Consequently, the German experts are not issuing any comments on supportive and palliative treatment. It will be necessary to await the published manuscript. The focus will be on managing chemotherapy-induced peripheral neuropathy (CIPN), hand-foot syndrome (HFS) and mucositis and stomatitis.

The German experts refer to the current recommendations by AGO [1] and the publication in Colloquium Senologie 2017/2018 [28].

\section{ABC4 Statements by the Patient Advocacy Committee}

The $A B C$ conference deliberately and specifically promotes the communication and exchange of information between patient advocates and physicians. As in previous years, the Patient Advocacy Committee also holds a meeting at the ABC4 conference. A total of 82 patient advocates from Europe, Asia, the Middle East, Africa, Australia and North, South and Central America attended the conference in Lisbon. The Patient Advocacy Committee summarized the results of their work in four core statements which were presented and their importance underscored by the Australian panelist and long-time patient advocate Danielle Spence (Breast Cancer Network) at the plenary session of the ABC4 conference.

Proposals of the Patient Advocacy Committee:

- Every patient with advanced breast cancer should have access to the most recent therapeutic options and to new targeted therapies in properly certified centers.

- Every patient with advanced breast cancer should be treated by a specialized multidisciplinary team working at a specialized breast center or institution which works together with these certified centers. This also includes the specialized management of side effects and a nursing team specialized in dealing with metastatic breast cancer.

- Every patient with advanced breast cancer should be given information early on (if necessary, already in the early stages of disease) about questions related to long-term survival and options for palliative medicine.

- Quality assurance procedures must be implemented in every specialized center to ensure that patients receive quality-assured treatment and care at every stage of disease, from screening to diagnosis, rehabilitation, follow-up and palliative care.

On behalf of all the attending patient advocates, Spence expressed her thanks for the opportunity to attend the conference 
and for the chance to exchange information between patient advocates and with attending physicians.

The German experts support the proposals of the Patient Advocacy Committees and the statements. The patient advocates from Germany who attended the conference in Lisbon were Renate Haidinger, Doris Schmitt, and Eva Schumacher-Wulf. From a German perspective, the key demand is interdisciplinary cooperation at specialized centers. In addition to quality-assured oncological treatment, this must include the management of side effects as well as adequate palliative medical and supportive therapeutic choices which must be carefully explained to patients.

At the end of the ABC4 conference, a global alliance was set up with substantial German participation to coordinate global measures. The global alliance defined the following goals for the next two years:

- Goal 1: Double the median overall survival time of patients with advanced breast cancer to at least four years by 2025 .

- Goal 2: Improve the quality of life of patients with advanced breast cancer in clinical practice.

- Goal 3: Improve the availability of robust data on the epidemiology and therapeutic outcomes of advanced breast cancer.

- Goal 4: Improve the availability of and access to multidisciplinary facilities, including palliative, supportive and psychosocial care and support for patients, their families and caregivers. Ensure that patients receive the best possible therapy and care from insurance companies.

\section{Conclusion and Outlook}

The ABC4 conference once again offered an informative platform for discussions on the latest developments in advanced and metastatic breast cancer. The ABC consensus is an important contribution towards standardizing the therapy of advanced breast cancer at an international level and optimizing treatment worldwide. In this respect, the $A B C$ conference is a valuable addition to the St. Gallen consensus conference on early breast cancer. The next ABC5 Consensus Conference will be held on November 14-16, 2019.

\section{Note}

The meeting of the German specialists in Lisbon was supported and organized by the company AURIKAMED Institut $\mathrm{GmbH}$. The authors would like to thank Birgit-Kristin Pohlmann, Nordkirchen, for her editorial assistance when compiling the manuscript. The authors are solely responsible for the final contents of the manuscript.

\section{Conflict of Interest}

Michael Untch has no conflict of interest. Rachel Würstlein received honoraria from Celgene, Pfizer, Novartis, Roche, Eisai, AstraZeneca, Amgen, MSD, and Pierre Fabre. Norbert Marschner has no conflict of interest.

Diana Lüftner received honoraria from Celgene, Pfizer, Novartis, Roche, Eisai, AstraZeneca, Amgen, MSD, Pierre Fabre, and L'Oreal.

Doris Augustin has no conflict of interest.

Susanne Briest has no conflict of interest.
Johannes Ettl received honoraria from Celgene, Eisai, GSK, Janssen, Lilly, Novartis, Pfizer, and Roche, and received research funding from Celgene and travel funding from Celgene, GSK, Novartis, Pfizer, and Roche. Renate Haidinger has no conflict of interest.

Lothar Müller has no conflict of interest.

Volkmar Müller received honoraria from Amgen, AstraZeneca, Celgene, Daiichi-Sankyo, Eisai, Pfizer, Pierre-Fabre, Nektar, Novartis, Roche, TESARO, Teva, and Janssen-Cilag. Eugen Ruckhäberle received honoraria from Amgen, AstraZeneca, Celgene, Janssen-Cilag, Novartis, Pierre Fabre, and Roche. Nadia Harbeck received honoraria from Amgen, Celgene, Novartis, Pfizer, Roche, and Sandoz.

Christoph Thomssen received honoraria from Amgen, AstraZeneca, Celgene, Lilly, Novartis, NanoString, Pfizer, Puma, and Roche.

\section{References}

[1] Janni W; für die AGO Kommission Mamma. AGO Empfehlungen „Diagnostik und Therapie von Patientinnen mit frühem Brustkrebs“. Update 2018. Online: www.ago-online.de; last access: 14.03.2018

[2] Konsultationsfassung S3-Leitlinie „Früherkennung, Diagnostik, Therapie und Nachsorge des Mammakarzinoms“. Langversion 0.4.1. - August 2017. AWMF-Register-Nr.032-045OL. Online: www.awmf.org; last access: 13.11.2017, additional: www.leitlinienprogramm-onkologie.de; last access: 13.11.2017

[3] Cardoso F, Costa A, Norton L et al. 1st International consensus guidelines for advanced breast cancer (ABC 1). Breast 2012; 21: 242-252. doi:10.1016/j.breast.2012.03.003

[4] Cardoso F, Costa A, Norton L et al. ESO-ESMO 2nd international consensus guidelines for advanced breast cancer (ABC2). Breast 2014; 23: 489502

[5] Cardoso F, Costa A, Senkus E et al. ESO-ESMO 3rd international consensus guidelines for advanced breast cancer (ABC3). Breast 2017; 31: 244259

[6] Online: www.esmo.org/Guidelines/ESMO-Guidelines-Methodology; last access: 13.11 .2017

[7] Paluch-Shimon S, Pagani O, Partridge AH et al. ESO-ESMO 3rd international consensus guidelines for breast cancer in young women (BCY3). Breast 2017; 35: 203-217

[8] Baselga J, Campone M, Piccart $\mathrm{M}$ et al. Everolimus in postmenopausal hormone-receptor-positive advanced breast cancer. N Engl J Med 2012; 366: $520-529$

[9] Beck JT, Hortobagyi GN, Campone M et al. Everolimus plus exemestane as first-line therapy in $\mathrm{HR}^{+}$, HER2- advanced breast cancer in BOLERO-2. Breast Cancer Res Treat 2014; 143: 459-467

[10] Kornblum NS, Manola J, Klein P et al. PrECOG 0102: A randomized, double-blind phase II trial of fulvestrant plus everolimus or placebo in postmenopausal women with hormone-receptor positive, HER2-negative metastatic breast cancer resistant to aromatase inhibitor therapy. San Antonio Breast Cancer Symposium 2016; Abstract S1-02

[11] Finn RS, Martin M, Rugo HS et al. Palbociclib and letrozole in advanced breast cancer. N Engl J Med 2016; 375: 1925-1936

[12] Hortobagyi GN, Stemmer SM, Burris HA et al. Ribociclib as first-line-therapy for HR-positive, advanced breast cancer. N Engl J Med 2016; 375 : $1738-1748$

[13] Hortobagyi GN. Updated results from MONALEESA-2, a phase 3 trial of first-line Ribociclib + letrozole in hormone receptor-positive, HER2-negative advanced breast cancer. JCO ASCO 2017; 35 (15S): \#1038

[14] Christofanilli M, Turner NC, Bonarenko I et al. Fulvestrant plus palbociclib versus fulvestrant plus placebo for treatment of hormone-receptor-positive, HER2-negative metastasic breast cancer that progressed on previous endocrine therapy (PALOMA-3): final analysis of the multicentre, double-blind, phase 3 randomised controlled trial. Lancet Oncol 2016; 17: 425-439 
[15] Harbeck N, lyer S, Turner $\mathrm{N}$ et al. Quality of life with palbociclib plus fulvestrant in previously treated hormone receptor-positive, HER2-negative metastatic breast cancer: patient-reported outcomes from the PALOMA-3 trial. Ann Oncol 2016; 27: 1047-1054

[16] Robertson JFR, Bondarenko IM, Trishkina E et al. Fulvestrant 500 mg versus anastrozole $1 \mathrm{mg}$ for hormone receptor-positive advanced breast cancer (FALCON): an international, randomised, double-blind, phase 3 trial. Lancet 2016; 388: 2997-3005

[17] Hahnen E, Lederer B, Hauke J et al. Germline mutation status, pathological complete response, and disease-free survival in triple-negative breast cancer: secondary analysis of the GeparSixto randomized clinical trial. JAMA Oncol 2017; 3: 1378-1385

[18] Litton J, Rugo H, Ettl J et al. EMBRACA: A phase 3 trial comparing talazoparib, an oral PARP inhibitor, to physician's choice of therapy in patients with advanced germline BRCA-mutation breast cancer. San Antonio Breast Cancer Symposium 2017; Abstract GS6-07

[19] Vasen HF, Watson P, Mecklin JP et al. New clinical criteria for hereditary nonpolyposis colorectal cancer (HNPCC, Lynch syndrome) proposed by the International Collaborative group on HNPCC. Gastroenterology 1999; 116: 1453-1456

[20] Online: www.fda.gov/NewsEvents; last access: 03.12.2017

[21] Bartsch R, Berghoff A, Pluschnig U et al. Impact of anti-HER2 therapy on overall survival in HER2-overexpressing breast cancer patients with brain metastases. Br J Cancer 2012; 106: 25-31
[22] Bartsch R, Berghoff AS, Preusser M. Breast cancer brain metastases responding to primary systemic therapy with T-DM1. J Neurooncol 2014; 116: 205-206

[23] Bachelot T, Romieu G, Campone M et al. Lapatinib plus capecitabine in patients with previously untreated brain metastases from HER2-positive metastatic breast cancer (LANDSCAPE): a single-group phase 2 study. Lancet Oncol 2013; 14: 64-71

[24] Montemurro F, Ellis P, Delaloge $S$ et al. Safety and efficacy of trastuzumab emtansin in 399 patients with central nervous system metastases: exploratory subgroup analysis from the KAMILLA study. San Antonio Breast Cancer Symposium 2016; Abstract P1-12-10

[25] Von Minckwitz G, Procter M, de Azambuja E et al. Adjuvant pertuzumab and trastuzumab in early HER2-positive breast cancer. N Engl J Med 2017; 377: 122-131

[26] Martin M, Holmes FA, Ejletersen B et al. Neratinib after trastuzumabbased adjuvant therapy in HER2-positive breast cancer (ExteNET): 5-year analysis of a randomised, double-blind, placebo-controlled phase 3 trial. Lancet Oncol 2017; 18: 1688-1700

[27] Online: www.onkopedia.com/de/news/komplementaere-undalternative-therapieverfahren; last access: 12.11.2017

[28] Untch M, Harbeck N, Thomssen C. Colloquium 2017/2018. Oktober 2017. München: Lukon Verlag; 2017

[29] Dykewicz CA. Summary of the guidelines for preventing opportunistic infections among hematopoietic stem cell transplant recipients. Clin Infect Dis 2001; 33: 139-144 